\title{
As Primeiras "Universitárias" - Na Ciência Portuguesa
}

\author{
Raquel Gonçalves*
}

Nas últimas décadas do século XIX - principalmente após o Ultimato inglês - acentuou-se o desencanto da vida nacional. A dúvida permanente numa regeneração das circunstâncias envolventes teve como consequência um desequilíbrio social e existencial.

A instrução que o povo português (não) tinha passa a ser motivo de forte preocupação por parte de eruditos. Cinco milhões de habitantes era o quantitativo aproximado de almas lusas povoando continente e ilhas adjacentes. Destes, um recenseamento estimara em um milhão os que sabiam ler e escrever; tendo sido incluídos na contagem os que conseguiam soletrar ou escrever o seu nome próprio... Muito significativo: a fracção feminina fora considerada quase nula. ${ }^{1}$

Salvo raríssimas excepções e em raras actividades, as mulheres são inexistentes.

A educação das mulheres portuguesas, como forma da sua emancipação, surge em força neste período, não só por actuação e voz pública das próprias mulheres, onde se destacam os nomes de Maria Amália Vaz de Carvalho, Caïel (pseudónimo de Alice Evelina Pestana Coelho), Guiomar Torrezão, Carolina Michaëlis de Vasconcelos e Ana de Castro Osório, mas também pelas obras de autores masculinos de que se salientam "A Mulher e a Vida ou a mulher considerada debaixo dos seus principais aspectos: instrução secundária” do professor da Universidade de Coimbrà José Joaquim Lopes Praça, datada de 1872, e "A Mulher em Portugal: obra póstuma publicada em benefício de uma criança" de D. António da Costa, Ministro da Instrução, em 1892, a qual, como o próprio nome indica, veio a público após à sua morte e de forma muito incompleta.

Só em Novembro de 1906 é criado em Portugal o primeiro liceu feminino.

A Universidade ( $a$ Universidade de Coimbra) insere-se na regra. Vive em clima de decadência institucional-cultural, de hesitações e incoerências. E as críticas vêm, não só do exterior, mas igualmente de mestres e alunos: uns, defendem uma reestruturação do ensino que a torne num campo de investigação e dinamização criativa; outros, pretendem a sobrevivência de uma estrutura clerical. A forte agitação que levou ao encerramento das aulas em Março de 1902 alastrou às Politécnicas de Lisboa e do Porto e veio a repetirse em Março de 1903, Janeiro de 1906 e Março de 1907; esta última, tendo como pretexto a reprovação do candidato a doutor José Eugénio
Dias Ferreira, insere-se num movimento muito mais generalizado de contestação ao governo de João Franco. Em Maio de 1907 são mesmo encerradas as matrículas na Universidade e a greve académica estende-se pelas escolas de todo o país.

Mas há mulheres que as percentagens não vêem e outras escolas de ensino superior que serão universidades. Juntemos as duas partes e, neste espaço e tempo de intersecção, encontraremos as primeiras universitárias.

\section{NA ESCOLA POLITÉCNICA}

Portugal tem uma lenda que inclui Publia Hortensia de Castro e Évora, nascida em Vila Viçosa no século XVI. Terá frequentado a Universidade de Évora, sob controlo jesuíta. Terá mesmo escrito uma tese de licenciatura, subordinada ao tema

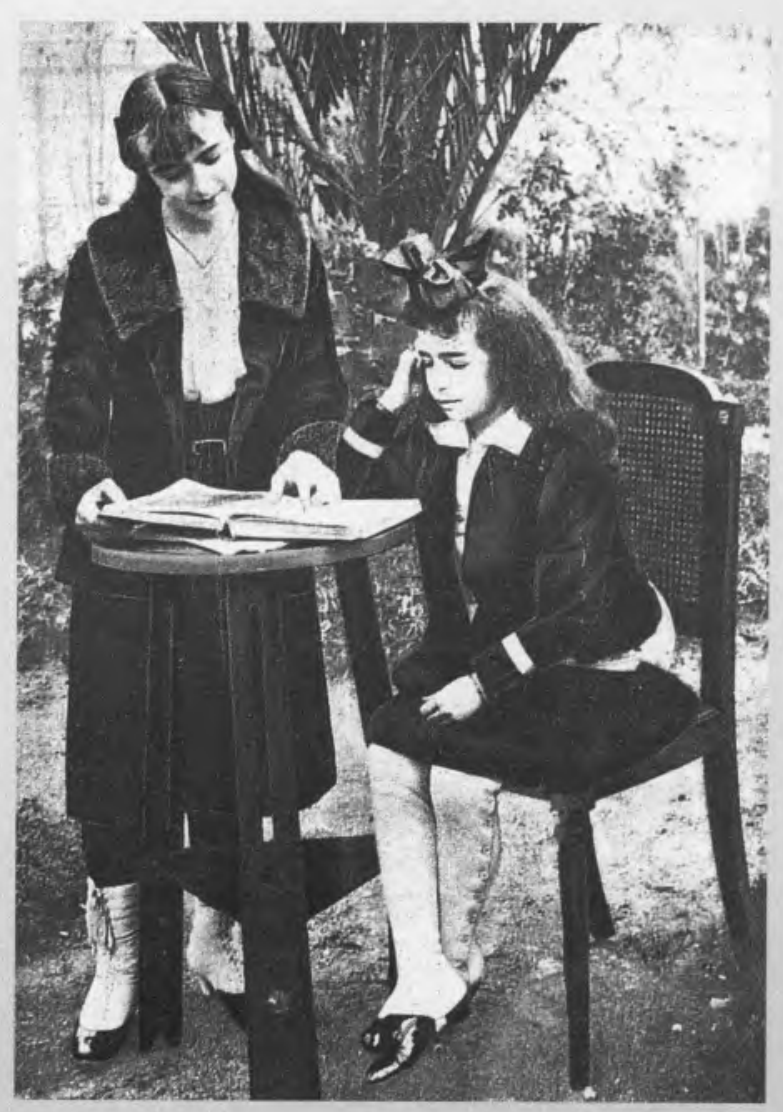

Fig. 1 - Hora da Leitura - A taxa de analfabetismo feminino no final do século XIX era elevadíssima 


\section{Elisa Augusta da Conceição Andrade}

Elisa Andrade, natural de Lisboa, foi a primeira mulher portuguesa que frequentou, em regime de voluntariado, uma instituição de ensino superior em Portugal. Ingressou, em 12 de Outubro de 1880, com 25 anos, na Escola Politécnica de Lisboa (mais tarde, Faculdade de Ciências da Universidade de Lisboa). O livro de "Matrículas e Exames" do Arquivo da Escola confirma a sua estadia até 1884 . Completou a $6^{a}$ Cadeira, Química Inorgânica, em Julho de 1881 (13 valores) e a cadeira de Análise Química e Química Orgânica, em Agosto de 1882 (10 valores). Quanto à $5^{a}$ Cadeira, Física Experimental, onde se matriculou em três anos consecutivos, só fez exame em Outubro de 1883 (10 valores). Em Julho de 1883 finalizou a $8^{a}$ Cadeira (11 valores) e em Julho de 1884 a $9^{a}$ Cadeira (12 valores).

Terá Elisa Andrade prosseguido os estudos? Algumas fontes indicam que terminou Medicina em 1889. que abriu consultório para senhoras e crianças e que terá mesmo realizado operações no primeiro hospital do país. Se assim foi, deve ser considerada a primeira médica portuguesa. Outras fontes, contudo, referem serem desconhecidos processo escolar e dissertação de licenciatura, presumindo-se que terá desistido.

"Filosofia Moral". E mais conta a lenda: que teve presença na Universidade de Coimbra, onde com seu irmão (Jerónimo de Castro) estudou Humanidades e Filosofia. Sempre vestida de homem, mantendo a sua identidade em segredo.

Mas segredo não é, decerto, nem lenda, a presença de Elisa Augusta da Conceição Andrade na Escola Politécnica de Lisboa (mais tarde, Faculdade

\section{Amélia Cardia dos Santos Costa}

Amélia Costa foi, seguramente, uma das primeiras cinco médicas portuguesas. Em 12 de Outubro de 1883 matriculou-se na Escola Politécnica, na classe de aluno ordinário. Entre esta data e Julho de 1887, frequentou e obteve aprovação em 5 disciplinas, o que lhe deu acesso à frequência da Escola Médico-Cirúrgica de Lisboa. A sua inscrição nesta escola foi solicitada em Outubro de 1886. Na Escola Médico-Cirúrgica frequentou e obteve aprovação em 12 disciplinas. Terminou o curso em 20 de Julho de 1891, em "acto grande", com a defesa da dissertação impressa $A$ Febre Hystérica. Tinha 35 anos de idade.

Foi a primeira mulher a trabalhar no internato hospitalar. Fundou uma Casa de Saúde, em 1908, na Estrela, instituição considerada modelar. Alguns anos mais tarde, abandonou a prática da Medicina e dedicou-se a estudos filosóficos e espiritas. Publicou contos, romances (Visionário, Pecadora, Alforria e Na Atmosfera da Terra), dirigiu $O$ Mensageiro Espirita e colaborou em diversos jornais e revistas (Ilustração Portuguesa, Século, Diário de Notícias, etc.). Foi membro da Associação das Ciências Médicas e da Federação Espirita Portuguesa. de Ciências da Universidade de Lisboa), no ano de 1880. Tinha 25 anos. O livro de matrículas confirma a sua estadia nesta Escola até 1884.

Elisa Andrade deve ser considerada, pois prova em contrário não existe, a primeira mulher portuguesa a frequentar o ensino superior. ${ }^{2}$

Em 1882 e 1883, Sofia Rosa da Silva e Amélia Cardia dos Santos Costa, respectivamente, iniciaram também os seus estudos superiores na Escola Politécnica. Aí fizeram os anos preparatórios de Medicina, tendo seguido para a Escola Médico-Cirúrgica de Lisboa, onde terminaram o curso em 1891.

O ritmo de acesso feminino ao ensino na Escola Politécnica de Lisboa foi muito lento. Até 1895 não se encontram matriculadas mais de $2 \mathrm{ou}$ 3 alunas (entre 1888 e 1993 não existe qualquer matrícula), o mesmo acontecendo entre 1896 e

\section{Adelaide de Jesus Damas Brazão e Cabette}

Adelaide Cabette, natural de Elvas, nasceu em 1867, descendente de uma familia modesta. Desde muito cedo foi obrigada a participar no sustento familiar através do seu trabalho numa fábrica local. Em consequência, não frequentou a escola primária, o que não a impediu de aprender a ler pelos seus próprios meios. Casou aos 18 anos de idade com Manuel Cabette, homem de qualidades invulgares, que a incentiva a estudar. Conclui, então, a instrução primária aos 22 anos, prossegue os estudos e licencia-se em Medicina, na Escola MédicoCirúrgica de Lisboa, em 1900, com 33 anos de idade. A maternidade e a criança foram os seus primeiros interesses como médica e pedagoga. Teve consultório aberto, deu aulas de puericultura e publicou muitos trabalhos. Presidiu à Alma Feminina, revista do Conselho Nacional das Mulheres Portuguesas. Foi membro da Sociedade das Ciências Médicas, co-fundadora da Liga Republicana das Mulheres Portuguesas (1909) e presidente do Conselho Nacional das Mulheres Portuguesas. Abraçou os ideais maçónicos, onde foi iniciada em 1907.

Recentemente, a escritora Lídia Jorge retirou-a do esquecimento e deu-Ihe vida em $A$ Maçon, peça em dois actos encenada em "navio fantasma" como símbolo dinâmico e enigmático, representada no Teatro Nacional (1997):

Tão perto e tão longe - Adelaide Cabette morreu em 1935, mas da sua personalidade singular e do seu desempenho social notável, como médica, pedagoga, publicista e benemérita, passado pouco mais de meio século, restam notícias vagas, partilhadas por muito poucos. Este esquecimento, porém, não se deve apenas ao espirito redutor de 1926, sagaz em sepultar, durante longas décadas, o nome daqueles que haviam querido a libertação. As raízes mais fortes do apagamento desta figura mergulham na dissensão do tempo que lhe foi contemporâneo, atravessado pela prática da cisão e da vingança que caracterizaram as primeiras décadas deste século. Adelaide Cabette, uma lutadora tão persistente quanto rebelde, viria a estar ligada a várias cisões, que ela mesmo interpretaria, sobretudo, a partir da sua perspectiva feminista de vanguarda, em colisão com as mulheres que aceitaram o minguado papel permitido pelos políticos da Primeira República.

Lídia Jorge, A Maçon (1997) 
1899. O ano de 1895 é excepcional para a Escola Politécnica: 4 alunas figuram nos seus livros de matrículas.

Merece especial referência o ano de 1894, ano em que se matricula Adelaide de Jesus Damas Brazão e Cabette, de 27 anos, natural de Elvas.

Em data incerta, ${ }^{3}$ mas também na Escola Politécnica, ter-se-á matriculado outra mulher pioneira do feminismo militante: Carolina Beatriz Ângelo. Licenciou-se igualmente na Escola Médico-Cirúrgica de Lisboa e, tal como Adelaide Cabette, evidenciou-se na luta pela igualdade de direitos e oportunidades, contribuindo para um melhoramento do estatuto social da mulher.

\section{Carolina Beatriz Ângelo}

Carolina Ângelo nasceu na Guarda, em 1877. Licenciou-se em Medicina em 1902. Foi, muito provavelmente, a primeira mulher a praticar cirurgia em Portugal.

Fundou e foi presidente da Associação da Propaganda Feminina, organização formada a partir de membros dissidentes da Liga Republicana das Mulheres Portuguesas. Foi uma defensora convicta dos direitos das mulheres. A participação feminina nos escrutínios nacionais sempre the pareceu o factor dominante na luta pela igualdade de direitos e usufruto de plena cidadania.

Tendo ficado viúva, lutou pelo seu direito de voto baseada na própria lei existente. (O direito de voto era concedido aos cidadãos maiores de 21 anos, que soubessem ler e escrever, ou fossem chefes de familia.) Requereu a sua inscrição como eleitora e, após luta em tribunal, ganhou o processo. O juiz de tal contenda foi o Dr. João Baptista de Castro, pai da conceituada feminista Ana de Castro Osório. Carolina Ângelo foi, então, a primeira mulher a exercer o direito de voto no nosso país - nas eleições legislativas de 28 de Maio de 1911. Este pioneirismo estende-se a todo o universo latino.

A sua morte ocorreu pouco depois, em 3 de Outubro de 1911

Não foi uma vitória feminista, mas foi um acto de rebeldia contra o preconceito da superioridade de sexo.

Revista Alma Feminina, Janeiro-Fevereiro de 1922

Como corolário do voto de Carolina Ângelo, a lei foi alterada ( 3 de Julho de 1913; ratificada em 1 de Julho de 1915), tendo sido eliminada radicalmente do sufrágio universal (!) a possibilidade de voto aos analfabetos... e aos cidadãos portugueses do sexo feminino.

Em 1916, o Senado defendeu o voto para as mulheres diplomadas, o que foi recusado pela Câmara dos Deputados. Nova insistência em 1918, pelo deputado Jacinto Nunes, teve igual fim. Só em 1931, o direito de voto foi concedido a algumas mulheres, as que possuíssem um curso secundârio ou superior.

\section{NA ACADEMIA POLITÉCNICA}

Foi em 1891 que mais duas mulheres terminaram Medicina, na Escola Médico-Cirúrgica do Porto. Foram elas as duas irmãs Aurélia e Laurinda de Morais Sarmento que tinham iniciado os seus estudos na Academia Politécnica (mais tarde, Faculdade de Ciências da Universidade do Porto), em 1885. Por sua vez, Maria Leite da Silva Tavares Paes Moreira iniciara-se um ano antes, com a idade de 27 anos, sendo a primeira mulher a integrar este instituto de ensino superior. Finalizou Medicina em 1892.

Em conjunto com as três presenças femininas no ensino superior em Lisboa atrás citadas, estamos em presença das primeiras cinco médicas portuguesas.

$\mathrm{O}$ acesso ao ensino superior na Academia Politécnica do Porto segue de perto o ritmo muito lento da sua congénere lisboeta.

\section{As irmãs Morais Sarmento}

As irmãs Aurélia e Laurinda de Morais Sarmento foram as primeiras mulheres que terminaram Medicina na Escola Médico-Cirúrgica do Porto, após frequência e aprovação nas cadeiras preparatórias na Academia Politécnica. Em 30 de Setembro de 1886, as irmãs matricularam-se na Escola Médica, onde estudaram as seguintes matérias (equivalentes às da Escola Médica em Lisboa): $1^{\text {a }}$ Cadeira - Anatomia; $2^{a}$ Cadeira - Fisiologia; $3^{a}$ Cadeira - Farmacologia ou Matéria Médica; $4^{a}$ Cadeira - Patologia e Terapêutica Externas; $5^{a}$ Cadeira Medicina Operatória (Operaçōes); $6^{\mathrm{a}}$ Cadeira - Obstetrícia (Partos); $7^{\text {a }}$ Cadeira - Patologia Interna; $8^{a}$ Cadeira - Clinica Médica; $9^{a}$ Cadeira - Clínica Cirúrgica; $10^{a}$ Cadeira Anatomia Patológica; $11^{\text {a }}$ Cadeira - Higiene e Medicina Legal e $12^{\text {a }}$ Cadeira - Patologia Geral.

Cinco anos volvidos, exactamente em 9 de Novembro de 1891, ambas concluíram o curso. No "acto grande", Aurélia de Morais Sarmento defendeu a tese Hygiene da Primeira Infância, tendo obtido como resultado "aprovação plena". O mesmo resultado foi atribuído a Laurinda na defesa da dissertação Hygiene do Vestuário Feminino.

A família Morais Sarmento, natural de Aveiro, era possuidora de grandes tradiçôes liberais. O pai, Anselmo Evaristo de Morais Sarmento, tinha uma cultura invulgar (fundou e dirigiu a Gazeta Literária do Porto, entre outros periódicos) e um posicionamento social de intolerância sobre a ancestral situação de inferioridade da mulher. Foi caso único na época que todos os seus cinco filhos, quatro raparigas e um rapaz, obtivessem graduação universitária. Além das duas filhas mencionadas, a terceira de nome Guilhermina terminou igualmente Medicina e a quarta, Rita, formou-se na Academia Politécnica, sendo a primeira Engenheira Civil portuguesa. 


\section{NA UNIVERSIDADE DE COIMBRA}

Só em 1891, no dia 8 de Outubro, a Universidade de Coimbra recebeu a primeira jovem: Dometilla Hormizinda Miranda de Carvalho de 20 anos de idade. Estudou Filosofia e Matemática. Até 1896 foi a única mulher a frequentar esta Universidade (entraram, então, Maria do Carmo Teixeira Marques e Sofia Júlia Dias, ambas para Matemática). Dometilla de Carvalho terminou o curso em 1898. Mais tarde, enveredou por Medicina que conclui em 1905.

\section{Dometilla Hormizinda Miranda de Carvalho}

Dometilla de Carvalho, natural da freguesia de S. Martinho de Travanca, concelho da Feira, foi a primeira mulher a obter a licenciatura (Matemática e Filosofia) pela Universidade de Coimbra, em 1898. Tinha 27 anos. Em 6 de Agosto desse ano, assim se pôde ler no Diário de Notícias:

A sra. D. Dometilla Miranda de Carvalho, que é formada nas faculdades de filosofia e matemática, obtendo sempre honrosas classificaçōes, tenciona receber o grau de doutor na faculdade de Coimbra, caso único, que nos conste, naquela prestigiosa universidade.

A distinta académica irá a Lisboa oferecer a sua pasta de quintanista com o seu retrato a sua majestade a rainha $s r^{a} D$. Amelia, que tem sido a sua protectora e convidando-a para madrinha do seu doutoramento.

Diário de Notícias, 6 de Agosto de 1898

Posteriormente, cursou Medicina, tendo-se formado em 1905. Dedicou-se ao ensino, onde atingiu posição dominante - foi reitora do Liceu D. Maria Pia (o primeiro liceu feminino, criado em 9 de Agosto de 1906 - e à política. Em 1935, tornou-se deputada da Assembleia Nacional. Igualmente talentosa na literatura, deixou escritas novelas e poesia.

\section{O PROGRESSO: NOMES SEM ACASO}

Em 1910, quando foi implantada a República, apenas 23 mulheres estavam matriculadas em instituições de ensino superior em Portugal. A Universidade de Coimbra, ainda a única existente, era frequentada por 1262 alunos, sendo 5 do sexo feminino.

Em 1911 (22 de Março) surgiu o decreto que criou a Universidade de Lisboa e a Universidade do Porto, reunindo cada uma delas as escolas de ensino superior já existentes.

Foi durante a segunda década do século XX que começaram a surgir das universidades portuguesas raparigas que se distinguiram nas suas profissões. Citamos o caso das médicas Eufrosina Teixeira, Branca Rumina e Sara Benoliel e das cientistas Branca Edmée Marques, Seomara da Costa Primo e Matilde Bensaúde, entre outras.
Nos anos 80, a mulher estudante atingiu no ensino universitário (na generalidade, mas não por especialidades) a mesma representatividade que tem na estrutura demográfica portuguesa. Nos anos 90 , ultrapassou-a. Hoje, mais raparigas do que rapazes frequentam a universidade e, mais significativo ainda, muitas mais terminam o seu curso superior.

A evolução citada trouxe, como é evidente, um contributo positivo para o estatuto social da mulher e para o seu usufruto de plena cidadania.

\section{* Departamento de Química e Bioquímica, \\ Faculdade de Ciências da Universidade de Lisboa}

\section{BIBLIOGRAFIA E NOTAS}

GUIMARÃES, Elina, Mulheres Portuguesas, ontem e hoje, col. "Cadernos Condição Feminina», n²4, Lisboa, 1989.

MORAIS, Maria Mantero e CARVALHO, José Eduardo, A Presença das Mulheres no Ensino Superior em Portugal, col. "Cadernos da Condição Feminina», n² 37, Lisboa, 1993.

PATRíCIO, Manuel Ferreira, A Instrução Pública: os limites de uma reforma, em Portugal Contemporâneo, dir. António Reis, vol. 2, Publicações Alfa, Lisboa, 1996.

PRAÇA, José Joaquim Lopes, A Mulher e a Vida ou a mulher considerada debaixo dos seus principais aspétos: instrução secundária, Livraria Portugueza e Estrangeira, Coimbra, 1872.

SANTOS, Cândido - A Mulher e a Universidade do Porto, Universidade do Porto, 1991.

SERRÃO, Joaquim Veríssimo, História de Portugal 1890-1910, vol. X, Verbo, Lisboa, 1990.

SILVA, Alda Pereira, CASACA, Cecilia e MASCARENHAS, João Mário, Adelaide Cabette - Alma de Mulher, Câmara Municipal de Lisboa, Lisboa, 1997.

SILVA, Maria Regina Tavares e VICENTE, Ana, Mulheres Portuguesas - Vidas e Obras Celebradas, Vidas e Obras ignoradas, Ditos \& Escritos, $n^{\circ} 1$, Comissão para a Igualdade e Direitos das Mulheres, 1991.

SILVA, Maria Regina Tavares, A Mulher - Bibliografia Portuguesa Anotada (Monografias, 1518-1998), Edições Cosmos, Lisboa, 1999.

1 O recenseamento, rigoroso, de Dezembro de 1911 indica os seguintes valores: 5950056 habitantes no continente e ilhas, contendo a cidade de Lisboa 435359 habitantes, isto é, cerca de $7,3 \%$ do total e a cidade do Porto 194000 , aproximadamente $3,2 \%$; a taxa de analfabetismo geral cifrou-se em $75,1 \%(82$ $83 \%$ nas mulheres; $65-68 \%$ nos homens), sendo muito superior no interior do continente e nas ilhas.

2 O Arquivo do Curso Superior de Letras, criado em Lisboa em 1859 , encontra-se em muito mau estado e não permite detectar as primeiras presenças femininas.

3 Os livros de matrículas da Escola Politécnica, entre 1894 e 1899 , não evidenciam o seu nome. 